CHRONIC OBSTRUCTIVE PULMONARY DISEASE

\title{
Quadriceps strength predicts mortality in patients with moderate to severe chronic obstructive pulmonary disease
}

\author{
Elisabeth B Swallow, Diana Reyes, Nicholas S Hopkinson, William D-C Man, Raphaël Porcher, \\ Edward J Cetti, Alastair J Moore, John Moxham, Michael I Polkey
}

Thorax 2007;62:115-120. doi: 10.1136/thx.2006.062026

See end of article for authors' affiliations

\section{Correspondence to:}

Dr E B Swallow, Respiratory Muscle Laboratory, Royal

Brompton Hospital, Fulham

Road, London SW3 6NP,

UK; e.swallow@

imperial.ac.uk

Received 8 March 2006

Accepted 9 September 2006

Published Online First

7 November 2006
Background: Prognosis in chronic obstructive pulmonary disease (COPD) is poorly predicted by indices of air flow obstruction, because other factors that reflect the systemic nature of the disease also influence prognosis. Objective: To test the hypothesis that a reduction in quadriceps maximal voluntary contraction force (QMVC) is a useful predictor of mortality in patients with COPD.

Methods: A mortality questionnaire was sent to the primary care physician of 184 patients with COPD who had undergone quadriceps strength measurement over the past 5 years. QMVC was expressed as a percentage of the patient's body mass index. The end point measured was death or lung transplantation, and median (range) follow-up was 38 (1-54) months.

Results: Data were obtained for 162 patients (108 men and 54 women) with a mean (SD) percentage of forced expiratory volume in $1 \mathrm{~s}\left(\mathrm{FEV}_{1}\right)$ predicted of 35.6 (16.2), giving a response rate of $88 \%$. Transplantfree survival of the cohort was $93.5 \%$ at 1 year and $87.1 \%$ at 2 years. Cox regression models showed that the mortality risk increased with increasing age and with reducing QMVC. Only age (HR 1.72 (95\% Cl 1.14 to 2.6); $p=0.01$ ) and QMVC (HR 0.91 (95\% Cl 0.83 to 0.99); $p=0.036$ ) continued to be significant predictors of mortality when controlled for other variables in the multivariate analysis.

Conclusion: QMVC is simple and provides more powerful prognostic information on COPD than that provided by age, body mass index and forced expiratory volume in $1 \mathrm{~s}$.
$\mathrm{C}$ hronic obstructive pulmonary disease (COPD) is the fourth leading cause of death in the world, ${ }^{1}$ but prognosis is only poorly predicted by indices of air flow obstruction. Given this limitation, a new severity classification, the Body Mass Index, Airflow Obstruction, Dyspnoea and Exercise Capacity (BODE) Index, ${ }^{2}$ has been proposed that takes into account the multicomponent nature of COPD with considerable emphasis being placed on the body mass index (BMI) as an indicator of poor prognosis. ${ }^{3-6}$ However, many investigators consider that it is, more specifically, the loss of skeletal muscle mass which confers a poorer prognosis in patients with COPD. ${ }^{7-10}$ Muscle mass depletion is associated with reduced exercise performance, ${ }^{11}{ }^{12}$ increased dyspnoea ${ }^{13}$ and worse health-related quality of life. ${ }^{14}$ Similarly, skeletal muscle weakness is a common finding in COPD and is associated with reduced exercise capacity. ${ }^{15-17}$ As exercise capacity is thought to be an important factor in determining mortality in $\mathrm{COPD},{ }^{18}$ it perhaps follows that muscle weakness should also predict mortality.

In a recent paper by Marquis et al, ${ }^{7}$ CT scanning was used to measure the mid-thigh cross-sectional area $\left(\mathrm{MTCSA}_{\mathrm{CT}}\right)$ in patients with COPD. This radiological measure of quadriceps bulk was shown to predict mortality better than BMI, and this was particularly so in patients with more severe COPD (forced expiratory volume in $\left.1 \mathrm{~s},\left(\mathrm{FEV}_{1}\right)<50 \%\right)$. This measure is attractive as a single reproducible predictor of mortality from COPD, but some obvious drawbacks limit its more widespread use. In particular the use of CT scanning has resource implications and involves a considerable exposure to radiation. We therefore hypothesised that a simple functional measure of strength, the quadriceps maximum voluntary contraction force (QMVC), might also predict mortality in patients with COPD.

\section{METHODS}

The study cohort comprised 184 patients with COPD, recruited without further selection from outpatient clinics at the Royal
Brompton Hospital (London, UK), a tertiary referral centre, and King's College Hospital (London, UK), in whom quadriceps strength measurements had been performed in the preceding 5 years. All patients underwent baseline anthropometric measurements including bioelectrical impedance analysis and pulmonary function tests, as well as quadriceps strength measurement. The primary end point was time to death or lung transplantation (termed transplant-free survival, TFS), calculated from the date when quadriceps strength was measured until the reference date of 20 July 2005, when the analysis was performed. The status of the patient (alive, dead or lung transplant recipient) was ascertained by a questionnaire sent to the patient's primary care physician. We also inquired about exacerbations of COPD that required hospital admission, smoking status, comorbidities, drug treatments and whether they had undergone a course of pulmonary rehabilitation. Patients were excluded from this study if they had considerable comorbidity. The Royal Brompton Hospital Research Ethics Committee approved the study.

\section{Pulmonary function testing}

All patients had COPD diagnosed according to international guidelines. ${ }^{19}$ Pulmonary function testing was performed by standardised techniques in the lung function departments of the Royal Brompton and King's College Hospitals. Patients were subdivided into Global Initiative for Chronic Obstructive Lung Disease (GOLD) stages on the basis of their $\mathrm{FEV}_{\mathrm{l}}$.

Abbreviations: $\mathrm{BMI}$, body mass index; $\mathrm{BODE}$, Body Mass Index, Airflow Obstruction, Dyspnoea and Exercise Capacity; COPD, chronic obstructive pulmonary disease; MTCSA ${ }_{C T}$, mid-thigh cross-sectional area measured by CT scanning; $\mathrm{FEV}_{1}$, forced expiratory volume in $1 \mathrm{~s}$; FFM, fat free mass; FFMI, Fat Free Mass Index; GOLD, Global Initiative for Chronic Obstructive Lung Disease; QMVC, quadriceps maximum voluntary contraction force; TFS, transplant-free survival 
Table 1 Demographics of the patients

\begin{tabular}{|c|c|c|}
\hline & $\begin{array}{l}\text { Complete patient data } \\
n=162 \text { (108 men, } \\
54 \text { women) } \\
\text { Mean (SD) }\end{array}$ & $\begin{array}{l}\text { No outcome data } \\
\mathrm{n}=22 \text { ( } 12 \text { men, } \\
10 \text { women) } \\
\text { Mean (SD) }\end{array}$ \\
\hline Age when tested (years) & $63.7(9.3)$ & $66.7(9.5)$ \\
\hline Height $(\mathrm{m})$ & $1.7(0.09)$ & $1.67(0.09)$ \\
\hline Weight (kg) & $70.2(16.3)$ & $70.4(15.7)$ \\
\hline BMI $\left(\mathrm{kg} / \mathrm{m}^{2}\right)$ & $24.4(5)$ & $25.2(4.7)$ \\
\hline FFMI in men $\left(\mathrm{kg} / \mathrm{m}^{2}\right)$ & $17.1(2.3)$ & $17.9(2.5)$ \\
\hline FFMI in women $\left(\mathrm{kg} / \mathrm{m}^{2}\right)$ & $15.8(2.3)$ & $15.7(1.7)$ \\
\hline $\mathrm{FEV}_{1}(\mathrm{l})$ & $0.98(0.44)$ & $1.02(0.3)$ \\
\hline $\mathrm{FEV}_{1} \%$ predicted & $35.6(16.2)$ & $42.2(9.3)$ \\
\hline DLCO \% predicted & $37.3(17.6)$ & $41.2(12.1)$ \\
\hline \multicolumn{3}{|l|}{ GOLD stage } \\
\hline 0 & $0(0 \%)$ & $0(0 \%)$ \\
\hline 1 & $2(1.2 \%)$ & $0(0 \%)$ \\
\hline 2 & $29(17.9 \%)$ & $3(13.6 \%)$ \\
\hline 3 & $56(34.6 \%)$ & $9(40.9 \%)$ \\
\hline 4 & 75 (46.3\%) & $10(45.5 \%)$ \\
\hline QMVC (kg) & $32.4(11.5)$ & 35.7 (13.3) \\
\hline QMVC as a \% of BMI & $135.5(46.7)$ & $142.7(50.5)$ \\
\hline \multicolumn{3}{|c|}{ 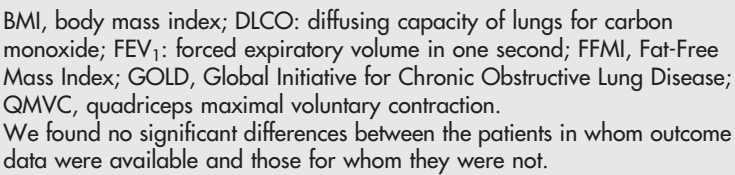 } \\
\hline
\end{tabular}

\section{Fat-free mass measurements}

Fat-free mass (FFM) was determined using bioelectrical impedance analysis (Bodystat 1500, Bodystat, Isle Of Man, UK) and a disease-specific regression equation. ${ }^{20}$

\section{Quadriceps Measurements}

QMVC was measured using the technique of Edwards et al. ${ }^{21}$ Patients sat in a purpose-built chair with an inextensible strap connecting the ankle of their dominant leg to a strain gauge (Strainstall, Cowes, UK). The force signal was amplified and passed to a computer running LabView version 4.1 software (National Instruments, Austin, Texas). The linearity of the strain gauge is factory certified from 0 to $100 \mathrm{~kg}$. The equipment was calibrated using a suspended weight before testing each patient. Care was taken to ensure that patients' knees were flexed to $90^{\circ}$, and that all the strain gauge and couplings were all aligned to ensure that the contraction was isometric. Patients performed at least three sustained maximal isometric quadriceps contractions of between 5 and $10 \mathrm{~s}$ duration. The force produced was visible online to both the patient and investigator to allow positive feedback, and vigorous encouragement was given. There was a gap of 30-60 s between each contraction to allow time to recover from each effort. The best QMVC was then expressed as a function of the patient's BMI.

\section{Statistical analysis}

TFS distribution was estimated using the Kaplan-Meier product moment estimator. A univariate analysis, based on the Cox proportional hazards model, where survival status at 20 July 2005 was used as the dependent variable, was performed to identify prognostic factors for TFS. Variables considered were age (divided into 10-year groups), BMI, Fat-Free Mass Index (FFMI), FEV 1 (percentage predicted) and QMVC (as a percentage of BMI). A multivariate Cox model was then fitted, in which all factors were considered. A stepwise backward variable selection procedure was implemented to remove the non-significant variables from the multiple models. The validity of the proportional hazards assumptions was assessed using the Grambsch and Therneau goodness-of-fit test ${ }^{22}$ and the validity of the log-linearity assumptions by fitting generalised additive models with splines to the residuals. Additionally, the discriminative ability of different multiple models was compared using the D measure of Royston and Sauerbrei, ${ }^{23}$ as well as the D-based version of Kent and $\mathrm{O}^{\prime}$ Quigley' $\mathrm{s}^{24}$ measure of dependence $\left(\mathrm{R}^{2}\right.$ measure). Data are expressed as mean (SD) values unless otherwise stated.

\section{RESULTS}

The response rate to the questionnaire was $88 \%$, and therefore the data expressed in this paper are for 162 patients ( 108 men and 54 women). Table 1 shows the patient demographics, and there were no significant differences between the patients in whom we obtained outcome data and those in whom we did not. During follow-up, 36 deaths occurred, as well as 2 lung transplants, and 31 patients had at least 1 hospital admission owing to an exacerbation of COPD ( 3 followed by death and 1 by a lung transplant).

All patients received standard treatment for COPD, with 20 patients taking long-term oral steroids at the time of quadriceps measurement. Nineteen patients were continuing smokers at the time of measurement. Seventy four patients had completed or subsequently completed a course of pulmonary rehabilitation. Patients with serious comorbidity were excluded from the analysis (ie, their primary care physician was not sent a questionnaire), and of the remaining cohort, 11 patients had treated hypertension, eight had mild ischaemic heart disease and one had type 2 diabetes mellitus.

Most of the patients had moderate to severe COPD that reflects the type of patients seen in hospital outpatient clinics in the UK. Figure 1 shows the TFS curve of the cohort. As only two patients were followed up for $>4$ years, one of whom died, the data were censored at 4 years. The median length of follow-up was 38 months, with a range of 1-54 months. The TFS of the cohort was $93.5 \%$ at 1 year and $87.1 \%$ at 2 years. The TFS curves for patients with normal and reduced quadriceps strength (QMVC $\geqslant 120 \%$ or $<120 \%$ of BMI, respectively) were significantly different ( $p=0.017$; fig 2$)$. The TFS separated by the GOLD stage shows that mortality increases with worsening lung function (fig 3). Although the curves show the expected trend, they do not reach significance (stages $0-2 \quad v \quad 3-4$; $\mathrm{p}=0.17$ )

Table 2 shows the results of univariate and multivariate Cox models. The univariate analysis shows that the mortality risk increased with increasing age and with reducing QMVC. Among all factors in the multivariate analysis, only age and QMVC wielded a significant association with survival. Diffusing capacity of the lungs for carbon monoxide was not considered in the multivariate analysis as data from 23 patients were missing. Being treated with oral steroids is a strong predictor of mortality: hazard ratio (HR) 3.68 (95\% confidence interval (CI) 1.84 to 7.34$) ; p=0.001$. No significant association was found between an acute exacerbation and the hazard of death or transplantation (HR $0.65,95 \%$ CI 0.23 to $1.88 ; \mathrm{p}=0.43$ ). In fact, only 3 of the 32 patients who had exacerbations died, compared with 32 of the 130 who did not. When compared with a model including age, sex, BMI and $\mathrm{FEV}_{1}$ (\% predicted), the selected model using only QMVC, sex and age yielded an explained variation $\left(\mathrm{R}^{2}\right)$ of $0.29 \vee 0.26$, indicating improved prognostic power. The $\mathrm{D}$ measure of prognostic discrimination for these models was $1.02 v 0.93$, in agreement with the previous result.

A review of the HRs for individual variables (fig 4) did not challenge the linearity hypotheses of the Cox models, nor Grambsch and Therneau's goodness-of-fit test (all $\mathrm{p}<0.25$ ). The relationship between the risk of death and increasing age and reducing QMVC seems roughly linear, whereas the relationship between $\mathrm{BMI}$ and $\mathrm{FEV}_{1}$ and the risk of death 


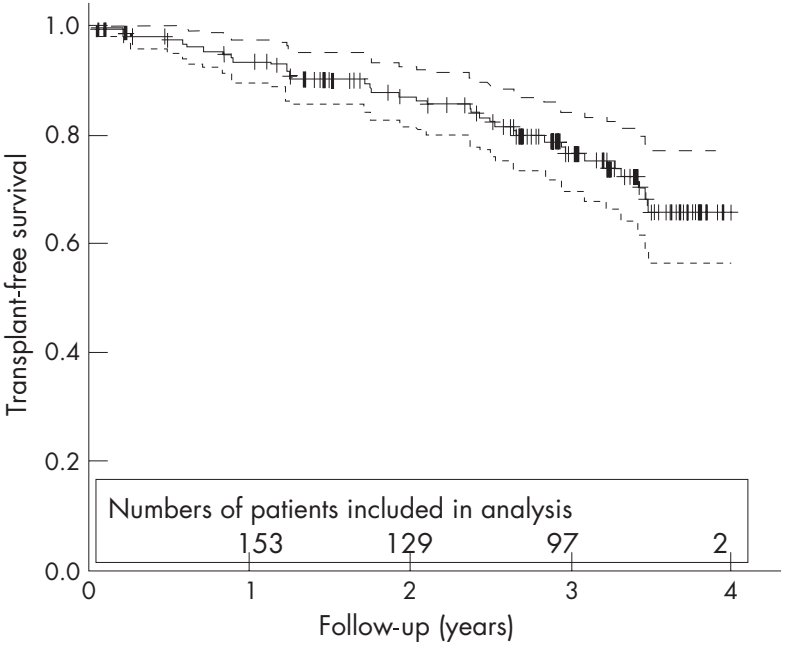

Figure 1 Transplant-free survival for the whole chronic obstructive pulmonary disese cohort (solid curve) with $95 \% \mathrm{Cl}$ (dashed line). Censoring times are represented by crosses $(+)$.

seemed, to visual inspection, flatter when considering a BMI between 20 and $30 \mathrm{~kg} / \mathrm{m}^{2}$ or an $\mathrm{FEV}_{1}<50 \%$ of predicted, suggesting poorer prognostic power in these ranges for these variables.

\section{DISCUSSION}

We found that, in patients with COPD, quadriceps muscle strength adds prognostic information to that provided by age, BMI and $\mathrm{FEV}_{1}$. We believe that, in common with MTCSA $\mathrm{CT}_{\mathrm{C}}$, QMVC reflects quadriceps muscle bulk and can be indicative of skeletal muscle dysfunction, but this physiological measurement is cheap and radiation free and may have greater functional relevance. Measurement of quadriceps strength could be used to identify high-risk patients with COPD who have peripheral muscle weakness and who may obtain greater benefit from rehabilitation or nutritional supplementation.

\section{Critique of the method}

Our questionnaire did not specify the cause of death so the data reflect all-cause mortality. The mortality in our study, an annual death rate of approximately $7 \%$, is similar to other studies on comparable patients, ranging from $5 \%$ in the study by Marquis et $a l^{7}$ to $9 \%$ in the study by Slinde et $a l^{8}$ We had a response rate of $88 \%$ from the questionnaires, and this was partly because of some patients no longer being registered with their original primary care physician. However, we doubt that the incompleteness of the data jeopardises our conclusions as both groups were similar with respect to baseline characteristics. We also acknowledge that as the Brompton Hospital acts as a tertiary referral centre, our patients may not be wholly typical of the generality of patients with COPD; our hypothesis should be retested in a primary care setting.

A further limitation of the study is that we measured only whole-body FFM rather than regional muscle bulk. Thus, we were unable to identify whether the poorer prognosis conferred by weakness is specifically due to a reduction in quadriceps bulk or a reduction in quadriceps specific force. Although this could be an interesting area for future study, it does not detract from the finding that QMVC has strong prognostic power.

Quadriceps strength in normal human beings bears a reasonably close relationship with total body weight, and Edwards et $a l^{21}$ recommended that quadriceps strength be normalised against body weight. This approach relied on an

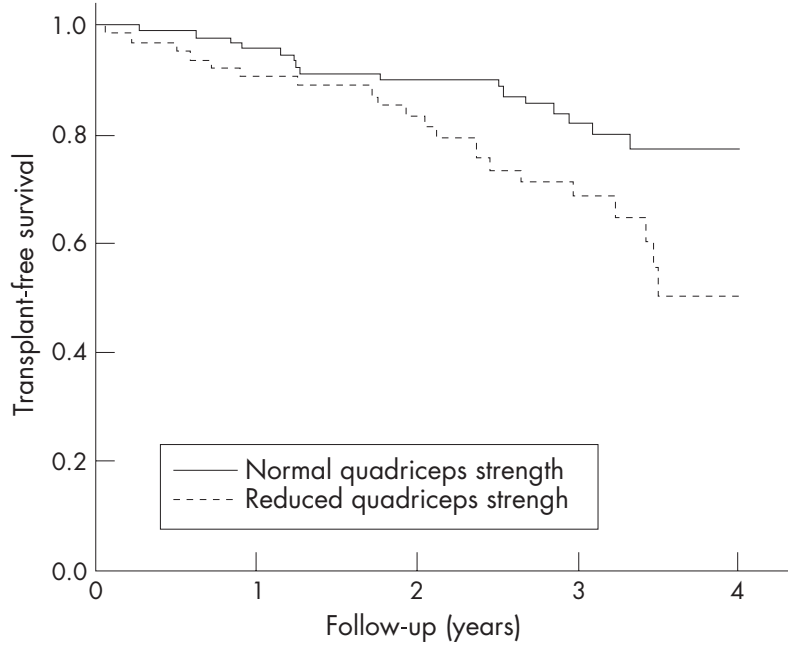

Figure 2 Transplant-free survival for patients with normal and reduced quadriceps strength, as defined by a quadriceps maximal voluntary contraction force $>120 \%$ or $<120 \%$ of body mass index. The curves are significantly different, $\mathrm{p}=0.017$.

unstated assumption that BMI did not vary greatly within his healthy population, and therefore that quadriceps muscle strength enjoyed a reasonably constant relationship with body weight (as a surrogate for height); in fact, Edwards et al ${ }^{21}$ reported neither the height nor BMI of their subjects. In patients with severe COPD, selective loss of quadriceps muscle bulk occurs, and as we hypothesised that it was this mechanism that confers the poor prognosis, it seemed inappropriate to discount the effect of height (and by inference femur length) on QMVC. For this reason, we expressed QMVC as a function of BMI. In addition, we performed analyses expressing QMVC as a function of body weight or FFM and this did not materially alter our conclusions, although the predictive power was slightly diminished with the body weight and increased with FFM.

QMVC is a non-invasive test, is simple to perform and gives a functional assessment of muscle bulk. Although we could additionally have performed magnetic stimulation of the femoral nerve, using the rationale that volitional measures are open to the criticism that weakness is due to reduced

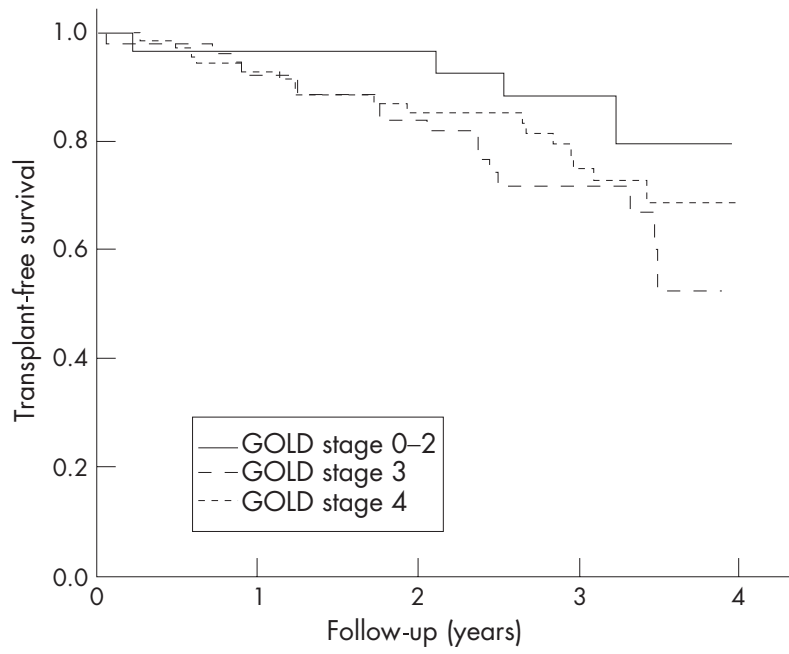

Figure 3 Transplant-free survival separated by Global Initiative for Chronic Obstructive Lung Disease (GOLD) stage. The curves were not significantly different (stages $0-2 \times 3-4 ; p=0.17$ ). 
Table 2 Assessment of prognostic factors using Cox proportional hazard models

\begin{tabular}{|c|c|c|c|c|}
\hline \multirow[b]{2}{*}{ Variable } & \multicolumn{2}{|l|}{ Univariate analysis } & \multicolumn{2}{|l|}{ Multivariate analysis } \\
\hline & $\mathrm{HR}(95 \% \mathrm{Cl})$ & p Value & $\mathrm{HR}(95 \% \mathrm{Cl})$ & p Value \\
\hline Men & 1.3 (0.64.to 2.62 ) & 0.47 & 1.61 (0.71 to 3.64$)$ & 0.25 \\
\hline Age (per 10 years) & 1.68 (1.19 to 2.36$)$ & 0.003 & $1.72(1.14$ to 2.6$)$ & 0.01 \\
\hline $\mathrm{BMI}\left(\mathrm{kg} / \mathrm{m}^{2}\right)$ & $0.96(0.9$ to 1.03$)$ & 0.3 & 0.91 (0.8 to 1.05 ) & 0.21 \\
\hline FFMI $\left(\mathrm{kg} / \mathrm{m}^{2}\right)$ & $0.96(0.82$ to 1.11$)$ & 0.58 & $1.08(0.81$ to 1.45$)$ & 0.6 \\
\hline $\mathrm{FEV}_{1}$ (\% predicted) & $0.99(0.97$ to 1.01$)$ & 0.17 & $0.98(0.96$ to 1.01$)$ & 0.13 \\
\hline DLCO (\%) & $0.97(0.95$ to 0.99$)$ & 0.016 & & \\
\hline QMVC (10\% of BMI) & 0.92 (0.85 to 0.99$)$ & 0.022 & 0.91 (0.83 to 0.99 ) & 0.036 \\
\hline Currently smoking & $1.79(0.82$ to 3.93$)$ & 0.14 & $2.06(0.85$ to 5$)$ & 0.11 \\
\hline Pulmonary rehabilitation & $0.95(0.5$ to 1.8$)$ & 0.88 & $1.57(0.75$ to 3.3$)$ & 0.23 \\
\hline
\end{tabular}

motivation or aptitude, ${ }^{25}$ we did not do this in most patients. The fact that QMVC emerged as a powerful prognostic indicator suggests that these reservations do not detract from the value of the measurement.

Exercise capacity or dyspnoea scores were not available for these patients; therefore, we were unable to calculate our cohort's BODE Index and could not compare our predictive model with that of Celli et al. ${ }^{2}$ However, exercise capacity is associated with quadriceps strength and the data show that our model, which includes only age, sex and quadriceps strength, is a useful predictor of mortality and is easier to perform. In the BODE grading system, the four variables that had the strongest association with l-year mortality (BMI, $\mathrm{FEV}_{1}$, modified Medical Research Council dyspnoea score and 6-min walk distances) had a generalised $\mathrm{R}^{2}=0.21$, whereas in our study, a model including age, sex and QMVC yielded an explained variation over the time course of the study of $\mathrm{R}^{2}=0.29$. Although direct comparison of the prognostic value of these two models is difficult as we are unable to compute the same data, the power of our model is at least of a similar order of magnitude.

\section{Importance of the findings}

In the general population, quadriceps weakness has been shown to be a predictor of mortality. ${ }^{26}$ Hence, our results are consistent with the hypothesis that factors that contribute to quadriceps weakness, such as inactivity, may also lead to reduced survival. However, the magnitude of the weakness observed in our patients with moderate to severe COPD is more marked than that observed in the normal population. We have previously shown that patients with COPD had a mean QMVC of $34.4 \mathrm{~kg}$ compared with $43.8 \mathrm{~kg}$ in the healthy, age-matched controls ${ }^{27}$; therefore we do not think our data simply reflect ageing.

Our findings suggest that quadriceps strength is a better marker at predicting mortality than either BMI or FFMI. In
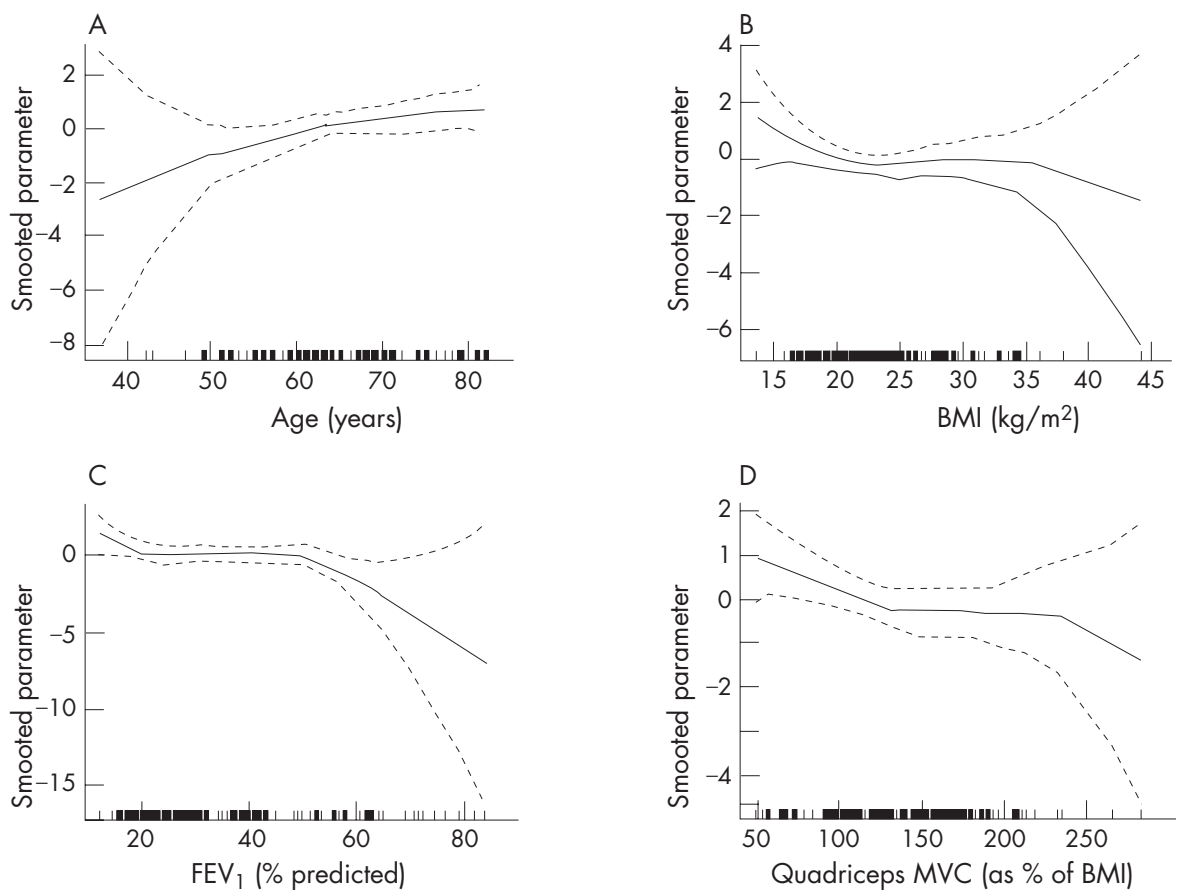

Figure 4 Test of functional form for (A) age, (B) body mass index (BMI), (C) forced expiratory volume in $1 \mathrm{~s}$ (FEV 1 ) percentage predicted and (D) quadriceps maximal voluntary contraction (QMVC) data. The y axis shows the spline estimates of log HRs for death (solid lines) with $95 \% \mathrm{Cl}$ (dashed lines) for each variable. The small lines on the $\mathrm{x}$ axis show where individual patients lie within the range. 
Marquis et al's study ${ }^{7}$ the subjects' mean BMI $\left(26 \mathrm{~kg} / \mathrm{m}^{2}\right)$ was in the normal range, yet the MTCSA $\mathrm{CT}_{\mathrm{CT}}$ values were $72 \%$ of the normal, which indicates that quadriceps muscle mass rather than body weight is the important physiological variable predicting survival. This suggests that the loss of muscle mass has more ominous implications for prognosis than the loss of other body compartments. Consistent with these data we did not find that FFMI was predictive of mortality, which is in contrast with other studies, ${ }^{8}{ }^{10}$ although absolute values for FFMI are not greatly different between these studies. The discordance between changes in FFM and quadriceps strength seems to support the importance of local rather than systemic factors in producing weakness.

In COPD, systemic factors such as inflammation, hypoxia and nutritional depletion may interact with local factors such as muscle activity level or perfusion to produce muscle weakness. The question remains as to the extent to which muscle weakness is a generalised, systemically determined phenomenon or one that predominantly affects the lower limbs as a result of disuse. The "compartment theory" is based on the premise that changes in muscle function depend on the demands placed on the muscle in question and is supported by the observation that different changes are found in different muscle groups. ${ }^{28}$ Thus, it is argued that patients walk less because of dyspnoea, which leads to disuse atrophy and quadriceps weakness. Upper limb strength is relatively maintained in patients with COPD, because there is a preservation of upper body activity and the shoulder girdle muscles are accessory muscles of respiration. ${ }^{17}$ Adductor pollicis twitch force is normal whereas quadriceps twitch is reduced in patients with COPD. ${ }^{29}$ Therefore, it is interesting that the mid-arm circumference, which reflects upper limb muscle bulk, has been shown to predict mortality. ${ }^{9}$ We have also recently shown that the expiratory muscles (which are active in patients with COPD) have at least normal strength in a cohort of patients with COPD. ${ }^{30}$ We therefore believe that the predominance of published data is in favour of the characteristic abnormality in COPD being an isolated locomotor muscle weakness.

The prognostic value of QMVC does not establish a causal relationship. Our study suggests that reduced quadriceps strength predicts mortality; however, it does not help in elucidating the reasons for this decline or when this begins in patients with COPD. We are not sure whether the natural history of quadriceps weakness is a slow deterioration, with disease progression or reduced activity, or, as suggested by the data of Spruit et $a l^{31}$ a stepwise decline associated with exacerbations. Only $17 \%$ of our cohort had an exacerbation requiring hospital admission during follow-up, indicating that the majority were not frequent exacerbators, despite most of the patients having quadriceps weakness. This suggests that serious exacerbations may not be necessary to cause quadriceps muscle deterioration. It is possible that quadriceps weakness is a surrogate marker for patients' reduced generalised performance status, but it may also be a systemic manifestation of generalised inflammation in COPD. It has been shown that reduced physical activity in itself is an independent risk factor for hospital admission. ${ }^{32}$ We do not know the effect of improving muscle strength on mortality, although our group has shown that early pulmonary rehabilitation after hospitalisation does improve quality of life and exercise capacity, and reduces further hospital attendances. ${ }^{33}$

In conclusion, quadriceps strength measured by a maximal voluntary isometric contraction is useful in predicting the mortality of patients with COPD. This easily performed measurement could be widely performed in the lung function laboratory and could serve to identify patients at higher risk of death.

\section{Authors' affiliations}

Elisabeth B Swallow, Diana Reyes, Nicholas S Hopkinson, Edward J Cetti, Alastair J Moore, Michael I Polkey, Respiratory Muscle Laboratory, Royal Brompton Hospital, London, UK

William D-C Man, John Moxham, Respiratory Muscle Laboratory, King's College London School of Medicine, Strand, London, UK

Raphaël Porcher, Department of Biostatistics and Medical Informatics, Hôspital Saint-Lovis, Paris, France

Competing interests: None.

\section{REFERENCES}

1 World Health Organization. World Health Report. Geneva: WHO, 2000.

2 Celli BR, Cote CG, Marin JM, et al. The Body-Mass Index, Airflow Obstruction, Dyspnea, and Exercise Capacity Index in chronic obstructive pulmonary disease. N Engl J Med 2004;350:1005-12.

3 Schols AMWJ, Slangen J, Volovics L, et al. Weight loss is a reversible factor in the prognosis of chronic obstructive pulmonary disease. Am J Respir Crit Care Med, 1998;157:1791-7.

4 Landbo $C$, Prescott $E$, Lange $P$, et al. Prognostic value of nutritional status in chronic obstructive pulmonary disease. Am J Respir Crit Care Med 1999; 160:1856-61.

5 Prescott E, Almdal T, Mikkelsen KL, et al. Prognostic value of weight change in chronic obstructive pulmonary disease: results from the Copenhagen City Heart Study. Eur Respir J 2002;20:539-44.

6 Chailleux E, Laaban J-P, Veale D. Prognostic value of nutritional depletion in patients with COPD treated by long-term oxygen therapy: data from the ANTADIR observatory. Chest 2003;123:1460-6

7 Marquis K, Debigare R, Lacasse Y, et al. Midthigh muscle cross-sectional area is a better predictor of mortality than body mass index in patients with chronic obstructive pulmonary disease. Am J Respir Crit Care Med 2002;166:809-13.

8 Slinde F, Gronberg A, Engstrom C-P, et al. Body composition by bioelectrical impedance predicts mortality in chronic obstructive pulmonary disease patients. Respir Med 2005;99:1004-9.

9 Soler-Cataluna JJ, Sanchez-Sanchez L, Martinez-Garcia MA, et al. Mid-arm muscle area is a better predictor of mortality than body mass index in COPD. Chest 2005; 128:2108-15

10 Schols AM, Broekhuizen R, Weling-Scheepers CA, et al. Body composition and mortality in chronic obstructive pulmonary disease. Am J Clin Nutr 2005;82:53-9.

11 Baarends E, Schols A, Mostert R, et al. Peak exercise response in relation to tissue depletion in patients with chronic obstructive pulmonary disease. Eur Respir $J$ 1997; 10:2807-13.

12 Schols AM, Mostert R, Soeters PB, et al. Body composition and exercise performance in patients with chronic obstructive pulmonary disease. Thorax 1991;46:695-9.

13 Sahebjami H, Sathianpitayakul E. Influence of body weight on the severity of dyspnea in chronic obstructive pulmonary disease. Am J Respir Crit Care Med 2000;161:886-90.

14 Mostert R, Goris A, Weling-Scheepers C, et al. Tissue depletion and health related quality of life in patients with chronic obstructive pulmonary disease. Respir Med 2000;94:859-67.

15 Hamilton AL, Killian KJ, Summers E, et al. Muscle strength, symptom intensity, and exercise capacity in patients with cardiorespiratory disorders. Am J Respir Crit Care Med 1995; 152(Pt 1):2021-31.

16 Gosselink R, Troosters T, Decramer M. Peripheral muscle weakness contributes to exercise limitation in COPD. Am J Respir Crit Care Med 1996; 153:976-80.

17 Bernard S, LeBlanc P, Whittom F, et al. Peripheral muscle weakness in patients with chronic obstructive pulmonary disease. Am J Respir Crit Care Med 1998; 158:629-34.

18 Oga T, Nishimura K, Tsukino M, et al. Analysis of the factors related to mortality in chronic obstructive pulmonary disease: role of exercise capacity and health status. Am J Respir Crit Care Med 2003;167:544-9.

19 Pauwels RA, Buist AS, Calverley PM, et al. Global strategy for the diagnosis, management, and prevention of chronic obstructive pulmonary disease. NHLBI/ WHO Global Initiative for Chronic Obstructive Lung Disease (GOLD) Workshop summary. Am J Respir Crit Care Med 2001;163:1256-76.

20 Steiner MC, Barton RL, Singh SJ, et al. Bedside methods versus dual energy $x$ rayabsorptiometry for body composition measurement in COPD. Eur Respir J 2002;19:626-31.

21 Edwards RH, Young A, Hosking GP, et al. Human skeletal muscle function description of tests and normal values. Clin Sci Mol Med 1977;52:283-90.

22 Grambsch PM, Therneau TM. Proportional hazards tests and diagnostics based on weighted residuals. Biometrika 1994;81:515-26.

23 Royston $\mathbf{P}$, Sauerbrei W. A new measure of prognostic separation in survival data. Stat Med 2004;23:723-48.

24 Kent JT, O'Quigley J. Measures of dependence for censored survival data. Biometrika 1988:75:525-34.

25 Man WD, Moxham J, Polkey MI. Magnetic stimulation for the measurement of respiratory and skeletal muscle function. Eur Respir J 2004;24:846-60.

26 Newman AB, Kupelian V, Visser M, et al. Strength, but not muscle mass, is associated with mortality in the health, aging and body composition study cohort. J Gerontol 2006;61:72-7. 
27 Hopkinson NS, Nickol AH, Payne J, et al Angiotensin converting enzyme genotype and strength in chronic obstructive pulmonary disease. Am J Respir Crit Care Med 2004; 170:395-9.

28 Gea JG, Pasto M, Carmona MA, et al. Metabolic characteristics of the deltoid muscle in patients with chronic obstructive pulmonary disease. Eur Respir J 2001;17:939-45.

29 Man WD, Soliman MG, Nikoletou D, et al. Non-volitional assessment of skeletal muscle strength in patients with chronic obstructive pulmonary disease. Thorax 2003:58:665-9.

30 Man WD-C, Hopkinson NS, Harraf F, et al. Abdominal muscle and quadriceps strength in chronic obstructive pulmonary disease. Thorax 2005;60:718-22.
31 Spruit MA, Gosselink R, Troosters T, et al. Muscle force during an acute exacerbation in hospitalised patients with COPD and its relationship with CXCL8 and IGF-I. Thorax 2003;58:752-6.

32 Garcia-Aymerich J, Farrero E, Felez MA, et al. Risk factors of readmission to hospital for a COPD exacerbation: a prospective study. Thorax 2003;58:100-5.

33 Man WD-C, Polkey MI, Donaldson N, et al. Community pulmonary rehabilitation after hospitalisation for acute exacerbations of chronic obstructive pulmonary disease: randomised controlled study. BMJ 2004;329:1209.

\section{Clinical Evidence-Call for contributors}

Clinical Evidence is a regularly updated evidence-based journal available worldwide both as a paper version and on the internet. Clinical Evidence needs to recruit a number of new contributors. Contributors are healthcare professionals or epidemiologists with experience in evidence-based medicine and the ability to write in a concise and structured way.

Areas for which we are currently seeking contributors:

- Pregnancy and childbirth

- Endocrine disorders

- Palliative care

- Tropical diseases

We are also looking for contributors for existing topics. For full details on what these topics are please visit www. clinicalevidence.com/ceweb/contribute/index.jsp

However, we are always looking for others, so do not let this list discourage you.

Being a contributor involves:

- Selecting from a validated, screened search (performed by in-house Information Specialists) epidemiologically sound studies for inclusion.

- Documenting your decisions about which studies to include on an inclusion and exclusion form, which we keep on file.

- Writing the text to a highly structured template (about 1500-3000 words), using evidence from the final studies chosen, within 8-10 weeks of receiving the literature search.

- Working with Clinical Evidence editors to ensure that the final text meets epidemiological and style standards.

- Updating the text every 12 months using any new, sound evidence that becomes available. The Clinical Evidence in-house team will conduct the searches for contributors; your task is simply to filter out high quality studies and incorporate them in the existing text.

If you would like to become a contributor for Clinical Evidence or require more information about what this involves please send your contact details and a copy of your CV, clearly stating the clinical area you are interested in, to CECommissioning@bmigroup.com.

\section{Call for peer reviewers}

Clinical Evidence also needs to recruit a number of new peer reviewers specifically with an interest in the clinical areas stated above, and also others related to general practice. Peer reviewers are healthcare professionals or epidemiologists with experience in evidence-based medicine. As a peer reviewer you would be asked for your views on the clinical relevance, validity, and accessibility of specific topics within the journal, and their usefulness to the intended audience (international generalists and healthcare professionals, possibly with limited statistical knowledge). Topics are usually 1500-3000 words in length and we would ask you to review between 2-5 topics per year. The peer review process takes place throughout the year, and out turnaround time for each review is ideally 10-14 days.

If you are interested in becoming a peer reviewer for Clinical Evidence, please complete the peer review questionnaire at www.clinicalevidence.com/ceweb/contribute/peerreviewer.jsp 